\title{
RESEARCH OF THE DEPENDENCE OF THE RESISTANCE OF ASYNCHRONOUS GENERATORS WITH MASSIVE ROTORS ON THEIR DESIGN
}

\author{
Yu.M. Bobozhonov ${ }^{1}$, K. M. Reymov ${ }^{1}$, B.T. Seytmuratov ${ }^{1}$, Khakimov T.Kh. ${ }^{2}$ \\ ${ }^{1}$ Karakalpak State University \\ ${ }^{2}$ Tashkent State Technical University named after Islam Karimov, Uzbekistan
}

\begin{abstract}
The article presents the results of a study of the dependence of the resistances of induction generators with massive rotors on their various designs, based on the experimentally taken frequency characteristics.
\end{abstract}

\section{Introduction}

Currents will be induced in a massive rotor in a rotating magnetic field. These currents will flow along the rotor and close at the ends. As is known, in a smooth massive rotor, currents propagate in the surface layer, the depth of which depends on the frequency of the current. The lower the frequency, the greater the penetration depth of these currents. Thus, with decreasing slip, the depth of current penetration will increase, and the active resistance of the rotor will decrease. The rotor scattering reactance will increase with decreasing slip.

\section{Main part}

As sliding approaches zero, the values of active and reactive resistance will approach some constant values.

When analyzing electric power systems, the characteristics of rotating machines are sought to be simplified in every possible way. Such a simplification, however, can lead to a number of fundamental errors in the calculations of energy systems. This includes, first of all, the question of the effect of current displacement and saturation in machines [1-3].

The frequency response of rotating machines is a set of steady-state complex values of stator currents when the slip of the rotor changes from 0 before $+\infty$.

If we construct the frequency characteristic of the operation of synchronous machines with different rotor slips, then its current diagram must be represented in the form of complex curves - a curve corresponding to the parameters along the longitudinal axis $d$, and a curve corresponding to the parameters along the transverse axis q.

Actual frequency characteristics are curves that bear little resemblance to the corresponding calculated circles [4-6].

In large synchronous hydrogenerators, for example, it is necessary to use a large section of copper in the rotor.
In this case, there is a strong displacement of the current in the copper of the rotor with an increase in its rotation frequency, which sharply distorts the corresponding geometrical place of the stator currents as a function of frequency.

In synchronous turbine generators there is a powerful rotor array with a complex pattern of magnetic flux penetration into steel, slot wedges made of non-ferrous metal, etc., therefore, the equivalent circuit of the machine essentially corresponds to the circuit with distributed constants. The equivalent generator parameters are highly slip dependent [7-9].

Previous studies show that the introduction of asynchronous turbine generators (ATG) into the composition of electric power systems leads to an increase in their static and dynamic stability under steady-state and transient conditions [10-13].

Ensuring the reliable operation of the ATG as part of the electric power systems should also be based on their updated calculations of steady-state and transient processes. The usually accepted equivalent circuit with one circuit in the rotor will be insufficient here.

The solution of these problems is possible if there is complete information about the electromagnetic parameters of the ATG in the form of frequency characteristics or complex equivalent equivalent circuits of all its circuits; existing in the form of closed windings or in the form of circuits corresponding to the massive parts of the rotor.

The question of their frequency characteristics is of great practical importance for ATGs with massive rotors, where their parameters, as a result of displacement of the current in the rotor and saturation of the magnetic paths, especially the toothed zone, usually vary widely in comparison with the parameters of synchronous turbogenerators.

Experimental studies to determine the frequency characteristics of ATGs with various massive rotors were carried out on an electrodynamic model of the Department 
of Electrical Networks and Systems of Tashkent State Technical University, which contains model ATGs with massive rotors of the following configurations: smooth, toothed and two squirrel-cage rotors with copper rods in the amount $Z_{2}=48$ and $Z_{2}=80$ pieces [14-16].

Determination of the frequency characteristics of model ATGs with various massive rotors was carried out by the method of damping of direct current in the stator windings by oscillography, with a stationary rotor, then bringing them to a rotating one, that is, by a method that has become widespread in studies of the frequency characteristics of large rotating machines.

The essence of this method is to use the connection between the set of steady-state modes when the electromagnetic system is supplied with voltages of different frequencies (frequency response) and the transient process that takes place in the system when the constant unit voltage is turned off, set by the Fourier transform, similar to the Laplace transform, after replacing the operator in the latter $\mathrm{p}$ sliding js.

$$
\mathrm{I}_{\mathrm{s}}(\mathrm{js})=1 / \mathrm{X}(\mathrm{js})=\mathrm{j}_{\mathrm{s}} \int_{0}^{\infty} i(t) e^{-j s t} d t
$$

where: $\mathrm{X}(\mathrm{js})$ - complex inductive reactance Damped current is approximated by the sum of exponentials;

$$
i(t)=i 1 e^{-\lambda 1 t}+i 2 e^{-\lambda 2 t} \ldots+i n e^{-\lambda n t}
$$

where: $i_{1}+i_{2}+i_{3}+\ldots+i_{n}=i_{0}-\mathrm{DC}$ initial value $i n, \lambda^{\prime} n=$ $1 / T_{n}$ - the initial value and attenuation coefficient of the nth exponential component of the experimental attenuation curve.

In this case, the frequency response is (js) takes the form:

\begin{tabular}{|l|l|l|l|l|}
\hline Parametrs & from K3MP $Z_{2}=80$ & from K3MP $Z_{2}=48$ & from K3MP $Z_{2}=48$ & from $\Gamma \mathrm{MP}$ \\
\hline$i_{1}($ o.e $)$ & 0.25787 & 0,26146 & 0,67826 & 0,81545 \\
\hline$i_{2}(\mathrm{o} . \mathrm{e})$ & 0,74119 & 0,74063 & 0,31925 & 0,12334 \\
\hline$i_{3}(\mathrm{o.e})$ & - & - & - & 0,05641 \\
\hline$\lambda_{1}(1 / \mathrm{c})$ & 2,5818 & 2,1111 & 3,4931 & 2,0477 \\
\hline$\lambda_{2}(1 / \mathrm{c})$ & 61,9805 & 64,1026 & 79,1766 & 24,7427 \\
\hline$\lambda_{3}(1 / \mathrm{c})$ & - & - & - & 169,6641 \\
\hline
\end{tabular}

As can be seen from the table, the presence of a third circuit with a high damping coefficient at the GMR is a consequence of the relatively strong manifestation of the current displacement effect, due to which the kinetic energy stored in the rotor is almost rapidly dissipated. Consequently, the electromagnetic and electromechanical oscillations of the parameters of the ATG with a smooth massive rotor are intensely suppressed in comparison with the ATG with squirrel-cage rotors, which are confirmed by the oscillograms of the phase currents of the threephase short circuit [21-23].

The presence of a periodic component in the phase currents of the stator of the ATG with KZMR is due to the fact that the presence of a copper cage ensures the directional flow of the rotor currents and thus the equivalent scattering resistance of the rotor circuit

$$
\begin{gathered}
i_{\mathrm{s}}(\mathrm{js})=\mathrm{j} /(\mathrm{r} / \mathrm{s}+\mathrm{jx}(\mathrm{js}))=i 1 \lambda 1^{\prime} \mathrm{js} /\left(\mathrm{js}+\lambda 1^{\prime}\right)+ \\
i 2 \lambda 2^{\prime} \mathrm{js} /\left(\mathrm{js}+\lambda 2^{\prime}\right)+\ldots=\mathrm{a}+\mathrm{jb}
\end{gathered}
$$

here: $\mathrm{a}=\mathrm{s}^{2}\left(i_{1} \lambda_{1}{ }^{\prime} /\left(\mathrm{s}^{2}+\left(\lambda_{1}{ }^{\prime}\right)^{2}\right)+i_{2} \lambda_{2}{ }^{\prime} /\left(\mathrm{s}^{2}+\left(\lambda_{2}{ }^{\prime}\right)^{2}\right)+\ldots\right)$

$$
\mathrm{b}=\mathrm{s}\left(i_{1}\left(\lambda^{\prime}\right)^{2}\left(\mathrm{~s}^{2}+\left(\lambda_{1}{ }^{\prime}\right)^{2}\right)+i_{2}\left(\lambda_{2}{ }^{\prime}\right)^{2} /\left(\mathrm{s}^{2}+\left(\lambda_{2}{ }^{\prime}\right)^{2}\right)+\ldots\right)
$$

All values in equality are expressed in relative units.

Calculations and graphical constructions of the frequency characteristics of the ATGs under consideration were based on the stator current reduced to the rated voltage. The initial value of the reduced stator current, according to the current decay oscillogram, is equal to $1 / \mathrm{r}$ in fractions of the nominal stator current, where the $\mathrm{dc}$ resistance $r$ of the attenuation loop is expressed in fractions of the basic stator resistance, i.e. $r$ $=0.01125$.

It should be noted that the experiments on damping of direct current in the ATG stator with various massive rotors were carried out under the same conditions. From the recorded oscillograms, the damped ATG currents with short circuit rotors had a steep slope in its initial part compared to the initial part of the damped ATG current with smooth and toothed rotors, which already testifies to the different electromagnetic properties of these machines [17-20].

As a result, two main exponential components were isolated from the ATT damping curves with squirrel-cage and gear rotors and three main components from the ATG curve with a smooth rotor, the corresponding initial values and damping coefficients of these components were also determined: decreases, which leads to a slow decay of the aperiodic component of the rotor current.

The basis for calculating the frequency characteristics of model ATGs was the well-known relationship:

$$
\begin{gathered}
i \operatorname{so}(\mathrm{js})=1 / \mathrm{X}(\mathrm{js})=i \mathrm{~s}(\mathrm{js}) /(1+\mathrm{j}(\mathrm{r} / \mathrm{s}) i \mathrm{~s}(\mathrm{js})) \\
i \mathrm{~s}(\mathrm{js})=\mathrm{a}+\mathrm{jb}
\end{gathered}
$$

Asking $S=0-\infty$, the required frequency characteristics of model ATGs with various massive rotors are obtained. Refinement of frequency characteristics in points $S=0$, $\mathrm{S}=1$ и $\mathrm{S}=\infty$ produced according to idle resistance $\mathrm{X}_{0}$, short circuit resistance $\mathrm{X \kappa}$, and the transition resistance $\mathrm{X}$, obtained from the experiments of no-load, short circuit and from the experience of supplying two phases with an alternating current equal to $3 \mathrm{~A}$. 
From a comparison of the obtained characteristics, it can be seen that the geometrical place of the end of the stator current vector of ATG with KZMR varies within wide limits than the currents of ATG with MZR and HMR, which means ATG with KMR is able to generate greater active power in comparison with others with the same structural dimensions of ATG. The frequency response of ATG with HMR is a complex curve, having a bulbous shape, due to the intensive displacement of the rotor current. As a result of the increased value of the inductive resistance of the rotor, the ATG with HMR has a slightly lower power factor and maximum torque compared to the rest of the ATG [24-26].

Thus, on the basis of the foregoing, it seems possible to give a fairly accurate ATG equivalent circuit for various massive rotors, in which rotors from a variety of damper circuits are replaced mainly by two (three - GMR) damper circuits with parameters $\mathrm{r} / \mathrm{s}$ and $\mathrm{X}$. The values of these parameters can also be determined from the obtained frequency characteristics.

The ATG equivalent circuit in the general case is as follows:

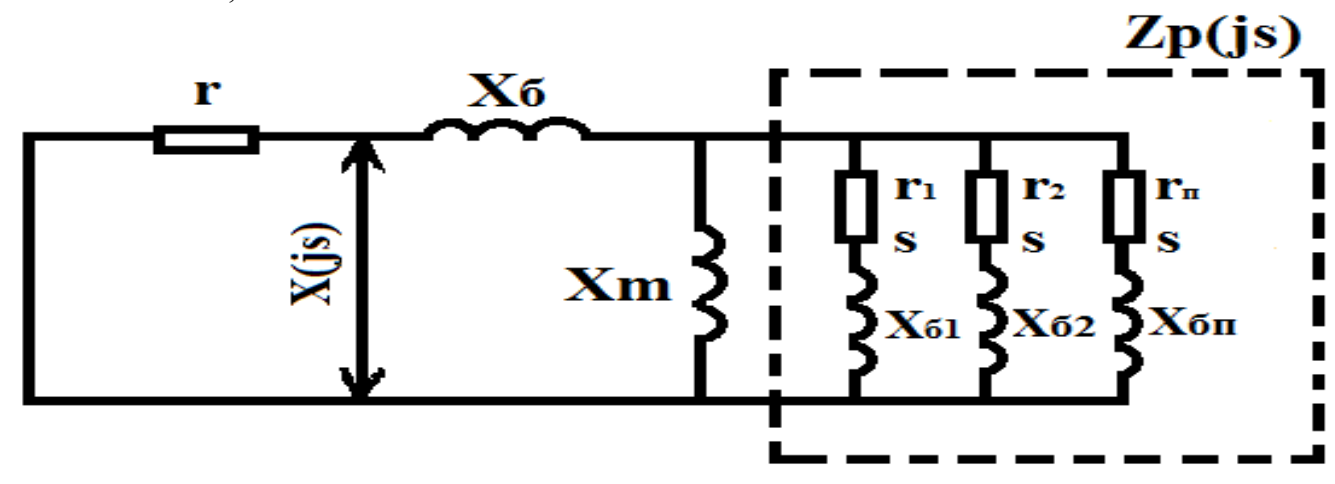

Frequency response $X(j s)$ through equivalent circuit parameters:

$$
\left.X(j s)=j X_{6}+j X m Z_{p}(j s) / j X_{m}+Z_{p}(j s)\right)
$$

Hence the equivalent frequency response of all circuits rotor:

$$
\mathrm{Z}_{\mathrm{p}}(\mathrm{js})=\mathrm{X}_{\mathrm{m}}\left(\mathrm{X}_{\sigma}+\mathrm{j} \mathrm{X}(\mathrm{js})\right) /\left(\mathrm{j} \mathrm{X}_{0}-\mathrm{X}(\mathrm{js})\right)
$$

where: $X_{0}=X_{m}+X$;

$X=0,4 * X_{K}-$ for ATG with GMR

$\mathrm{X}=0,5 * \mathrm{X}_{\mathrm{K}}-$ for ATG with MCH and KZMR.

On the other hand $Z_{p}(j s)$, written through the parameters of the damper circuits, has the form:

$$
\mathrm{Z}_{\mathrm{p}}(\mathrm{js})=1 / \sum\left(\mathrm{s} /\left(\mathrm{r}_{\mathrm{i}}+\mathrm{j} \mathrm{s} \mathrm{X}_{\text {бi }}\right)\right)
$$

Finally, determining the quantities $r_{i}$ and $X_{6 i}$, for example, with two and three damper circuits on a massive rotor, it is produced from a system of four and six equations composed according to this formula to the known values $Z_{\mathrm{p}}(\mathrm{js})$, defined for four and six slip points, respectively.

Thus, it can be concluded, referring to the results of the study, that the use of ATG with KZMR in an electric power system has a great technical advantage in comparison with other types of massive rotors.

\section{References}

1. Kh.F. Fazylov, K.R.Allayev "Large asynchronous turbine generators as necessary elements of modern electrical systems". Izvestia of the Academy of Sciences of the UzSSR. 1991. No. 5. Pages 45-54.

2. KR Allaev, MS Tashpulatov "Small hydroelectric power plants and the prospects for using asynchronous generators in them". Izvestia of the Academy of Sciences of the UzSSR. 1989. No. 1. Pages 22-25.

3. Yakushov V.M. "Experimental determination of frequency characteristics and electromagnetic parameters of synchronous generators". "Power stations". -1978. \# 1. pp. 47-51.

4. Toshov, Zh.B. Ways towards optimization of washout components of rock cutting tools Information about author // Gornyi Zhurnal. Volume 2016, Issue 2, 1 January 2016, Pages 21-24.

5. Burievich, T.J. The questions of the dynamics of drilling bit on the surface of well bottom// Arch. Min. Sci. -Poland. - Vol. 61 (2016). - №2. - P. 279-287. DOI 10.1515/amsc-2016-0020.

6. Toshniyozov, L.G., Toshov, J.B. Theoretical and experimental research into process of packing in drilling// Mining Informational and Analytical Bulletin Volume 2019, Issue 11, 2019, Pages 139-151. DOI: 10.25018/0236-1493-2019-11-0-139-151.

7. Avezova N.R., Toshov J.B., Dalmuradova N.N., Farmonova A.A., Mardonova M.Sh.Renewable Energy: Scenario and Model of Development // ISSN 0003-701X, Applied Solar Energy, 2019, Vol. 55, No. 6, pp. 438-445. DOI: $10.3103 / \mathrm{S} 0003701 \mathrm{X} 19060021$

8. Mannanov U., Toshov J., Toshniyozov L. Perspective Solutions for the Design of Drilling Tools / E3S Web of Conferences 105, 03027 (2019) IVth International Innovative Mining Symposium, https://doi.org/10.1051/e3sconf/201910503027

9. E.G.Usmanov, A.N.Rasulov, M.K.Bobojanov, R.Ch.Karimov. E3S Web of Conferences 139, 01079 (2019), doi.org/10.1051/e3sconf/201913901079;

10. Karimov R.Ch., Shamsiyeva N. and others. IOP Conf. Series: Materials Science and Engineering, 883(1), 012120, (2020). doi:10.1088/1757-899X/883/1/012120

11. G.R.Rafikova,

M.R.Ruzinazarov, S.K.Makhmutkhonov. E3S Web of Conferences, 139, 01075,

(2019),

https://doi.org/10.1051/e3sconf/201913901075

12. Toshov J., Saitov E. Portable autonomous solar power plant for individual use / E3S Web Conf., Volume 
139, 01087, 2019, Rudenko International Conference "Methodological problems in reliability study of large energy systems" (RSES 2019), https://doi.org/10.1051/e3sconf/201913901087

13. Azamatovich, A.N., Amrillo, M.B, Burievich, T.J., Umarxanoxich, J.R., Shavkatovich, Z.A. A complex of methods for analyzing the working fluid of a hydrostatic power plant for hydraulic mining machines / International Journal of Advanced Science and Technology. Volume 29, Issue 5 Special Issue, 28 March 2020, Pages 852-855 14. Andreev F. I. Theoretical foundations of electrical engineering. Uch. POS. Ekaterinburg. Two thousand three.

15. Rakhmonov, I. U., Tovbaev, A.N., Nematov, L.A., Alibekova,T.Sh. (2020) Development of forecasted values of specific norms for the issues of produced products in industrial enterprises Journal of Physics: Conference Series $\mathbf{1 5 1 5}$ doi:10.1088/1742$\underline{6596 / 1515 / 2 / 022050}$

16. Rakhmonov, I.U., Nematov, L.A., Niyozov, N.N, Reymov, K.M., Yuldoshev, T.M. (2020) Power consumption management from the positions of the general system theory Journal of Physics: Conference Series 1515 doi:10.1088/1742-6596/1515/2/022054

17. Rakhmonov, I. U., Reymov, K.M., Dustova, S.H. (2020) Improvements in industrial energy rationing methods Journal of IOP: Conference Series. MIP: Engineering-2020. 862 (2020) 062070 doi:10.1088/1757$\underline{899 X / 862 / 2 / 062070}$

18. Rakhmonov, I.U., Berdishev, A.A., Niyozov, N.N., Muratov, A., Khaliknazarov U. (2020) Development of a scheme for generating the predicted value of specific electricity consumption Journal of IOP: Conference Series. MIP: Engineering-2020. 883 (2020) 012103 doi:10.1088/1757-899X/883/1/012103

19. Rakhmonov, I.U., Berdishev, A.A., Khusanov, B.M., Khaliknazarov, U., Utegenov, U. (2020) General characteristics of networks and features of electricity consumers in rural areas Journal of IOP: Conference Series. MIP: Engineering-2020. 883 (2020) 012104 doi:10.1088/1757-899X/883/1/012104

20. Hoshimov, F.A., Bakhadirov, I.I., Erejepov, M., Djumamuratov, B. (2019) Development of method for normalizing electricity consumption E3S Web Conf 139 doi:10.1051/e3sconf/201913901074

21. Allayev, K.R., Fedorenko, G.M.,Postnikov, V.I.,Ostapchuk, L.B. Asynchronous generators as power system's natural dampers. 43rd International Conference on Large High Voltage Electric Systems 2010, CIGRE 20102010, 9p43rd International Conference on Large High Voltage Electric Systems 2010, CIGRE 2010; Paris; France; 22 August 2010.

22.Fazylov, Kh.F.,Allaev, K.R. Analysis of the operation of an electrical system during simultaneous operation of synchronous and asynchronous generators. Power engineering New York Volume 18, Issue 3, 1980, Pages 81-88.

23.Fazylov, Kh.F.,Allaev, K.R. Asynchronous turbogenerators with stator excitation and the prospects for their utilization. Power engineering New York Volume 23, Issue 2, 1985, Pages 7-13.
24.Fazylov, Kh.F.,Allaev, K.R. Calculation and experimental analysis of conditions of electrical power systems containing induction generators Power Engineering New York Volume 27, Issue 6, 1989, Pages 27-34.

25.Allaev K., Makhmudov T. Research of small oscillations of electrical power systems using the technology of embedding systems. Electrical Engineering, 2020; Issue 1: 309-319.DOI 10.1007/s00202-019-00876-9

26.Allaev K., Makhmudov T. Prospects of diversification and ensuring energy safety of Uzbekistan. E3S Web Conf., Volume 139, 2019, Rudenko International Conference "Methodological problems in reliability study of large energy systems" (RSES 2019).https://doi.org/10.1051/e3sconf/201913901002 